REVIEW

\title{
Nitric oxide: an emerging role in cardioprotection?
}

\author{
R D Rakhit, M S Marber
}

Over a decade of research has shown nitric oxide (NO) to be a ubiquitous modulator of biological phenomena from cell signal to effector and from physiology to pathophysiology. The involvement of NO in cardiovascular biology has contributed significantly to our understanding of complex disease states including atherosclerosis, systemic and pulmonary hypertension, endotoxic shock, pre-eclampsia, ${ }^{1}$ cardiomyopathy, ${ }^{2}$ and cardiac allograft rejection. ${ }^{3}$ However, the emerging role of $\mathrm{NO}$ in the maintenance of cell physiology from immunomodulation to calcium signalling has highlighted the importance of this fascinating molecule in cytostasis. This dichotomy of effector function is the "double edged sword" of NO in biological systems. However, the balance between cytostatic and cytotoxic effects of NO may lie in the tissue concentration of NO produced, the particular NO synthase (NOS) isoform activated (that is, "high output" or "low output"), and the complex interaction with other free radicals such as superoxide. However, a much greater understanding of the molecular and cellular actions of $\mathrm{NO}$ as a physiological regulator has resulted in a body of recent research increasing our understanding of $\mathrm{NO}$, and thus $\mathrm{NO}$ releasing agents, in cytoprotection. Current evidence is outlined below.

\section{The NO dichotomy: physiology versus pathology?}

NO is produced by the catalytic action of NOS on the substrate L-arginine. The reaction involves the oxidation of one of the guanidinonitrogens of arginine and the process involves the oxidation of NADPH (nicotinamide adenine dinucleotide phosphate, reduced form) and the reduction of molecular oxygen. Three NOS enzymes have been characterised: type I (ncNOS), type II (iNOS), and type III (ecNOS). ncNOS and ecNOS are calcium dependent and low output enzymes associated with NO production in the picomolar range, whereas iNOS is a calcium independent and high output enzyme associated with NO production in the nanomolar ( $\mathrm{nmol}$ ) range. All three NOS isoforms have been shown to be present in human myocardium ${ }^{4}$ and may be activated in response to hypoxia or ischaemia. Laboratory studies of experimental myocardial infarction have shown an increased induction of iNOS, ecNOS, and NO concentrations in the heart, together with increased plasma concentrations of nitrate and nitrite, the oxidation products of NO. ${ }^{5-7}$ The isoform specific amount of NO generated may account, in part, for physiological versus pathological effects of $\mathrm{NO}$ in biological systems; low concentrations are associated with cytostasis and high concentrations are associated with cytotoxicity. ${ }^{8}$

A further explanation for the dichotomous effects of NO may lie in its complex interaction with reactive oxygen species, which is particularly pertinent in the context of ischaemiareperfusion. NO can interact in direct equimolar concentrations with superoxide to form the potent oxidant peroxynitrite, which is toxic to cardiac myocytes. ${ }^{9}$ The amount of peroxynitrite production therefore depends on the ratio of superoxide to NO. The greater availability of superoxide may therefore favour peroxynitrite production and toxicity. Thus, superoxide may be an important rate limiting factor determining the protective versus toxic effects of $\mathrm{NO}^{10}$ Although the interaction of $\mathrm{NO}$ with reactive oxygen species is very complex, this simple hypothesis may explain why, even though the majority of animal studies have shown cytoprotective effects ${ }^{11-14}$ of NO against ischaemiareperfusion injury, others have shown cytotoxicity. ${ }^{15} 16$

Emerging evidence suggests that a fundamental explanation for the dichotomous roles of NO may lie at a subcellular level. NO has been shown to modulate mitochondrial function through reversible and irreversible interactions with respiratory chain complexes. ${ }^{17}$ Physiological concentrations of NO inhibit cytochrome oxidase (complex IV) in a reversible manner, in competition with oxygen. However, long term exposure can irreversibly inhibit complex I by S-nitrosation of critical thiols in the enzyme complex. The reversible interaction may play an important part in the physiological regulation of mitochondrial function by reducing oxygen consumption without causing adenosine triphosphate (ATP) depletion. This may be beneficial during ischaemia.

\section{Novel cellular mechanisms of protection} ANTIAPOPTOSIS

Apart from promoting apoptosis NO can also paradoxically inhibit apoptosis. Proposed mechanisms include the suppression of caspase 1 and 3 activity by NO induced S-nitrosation; 
cyclic guanosine monophosphate (GMP) mediated suppression of calcium mediated apoptotic cell death; and induction of the cytoprotective stress proteins heat shock protein 70 and heat shock protein 32 (haemoxygenase). ${ }^{18}$

\section{ANTIOXIDANT EFFECTS}

NO has been shown to induce the expression of haemoxygenase in vascular and smooth muscle cells. Haemoxygenase and carbon monoxide, the product of the breakdown of haeme by haemoxygenase, can bind the haeme moieties of NOS and soluble guanylate cyclase and thereby inhibit NO production. This may therefore provide a novel adaptive defence mechanism against the oxidative stress associated with sustained production of NO. ${ }^{19}$

ANTI-INFLAMMATORY EFFECTS

NO has for a long time been linked to the modulation of the immune response and effects on cell mediated immunity may have a role in cytoprotection. High doses of NO have been shown to modulate the production of interleukin 12 negatively, thus reducing the $\mathrm{T}$ helper cell 1 immune response. ${ }^{20}$ In addition NO appears to reduce polymorphonuclear leucocyte mediated endothelial dysfunction in myocardial ischaemia-reperfusion, probably through the specific interaction with adhesion molecules. $^{21}$

CYCLIC GMP

This important second messenger is produced by the action of $\mathrm{NO}$ on soluble guanylate cyclase, which catalyses the conversion of guanasine triphosphate (GTP) to cyclic GMP. Cyclic GMP may exert protective effects by reducing the influx of calcium through $\mathrm{L}$ type calcium channels and by stimulating a cyclic GMP sensitive phosphodiesterase with a resultant reduction in concentrations of cyclic AMP. This, together with the known effect of $\mathrm{NO}$ in reducing myocyte contractility, ${ }^{22}$ would serve to reduce oxygen consumption and energy demand.

PRECONDITIONING

Ischaemic preconditioning is a powerful adaptive phenomenon whereby exposure to period(s) of sublethal ischaemia protects against subsequent lethal ischaemia. NO may trigger an early preconditioned state, ${ }^{23}$ and an extensive body of evidence has implicated $\mathrm{NO}$ as a trigger and mediator of late preconditioning. ${ }^{24}$ The mechanism of protection by NO in late preconditioning may involve the mitochondrial potassium ATP dependent channe ${ }^{25}$ and the isoform selective activation of specific protein kinase $\mathrm{C}$ isoforms. ${ }^{26}$

MODULATION OF MITOCHONDRIAL FUNCTION A reversible suppression of mitochondrial respiration has been shown to explain myocyte adaptation to chronic hypoxia without compromising cell survival or accelerating ATP depletion. ${ }^{27}$ Recent studies have shown that NO is indeed a physiological regulator of myocardial oxygen consumption ${ }^{28}$ and that reduced oxygen consumption by this mechanism may contribute to cardioprotection during preconditioning. ${ }^{29}$ Mitochondrial dysfunction is a critical component of ischaemia-reperfusion injury, which is characterised by dissipation of the membrane potential, ATP depletion, induction of the mitochondrial permeability transient, and mitochondrial calcium overload. $^{30}$ We have data to suggest that $\mathrm{NO}$ induced depolarisation of the mitochondrial membrane potential protects cardiomyocytes by reducing mitochondrial calcium overload during hypoxia-reoxygenation injury. ${ }^{31}$ This may be a novel explanation linking the NO mediated modulation of mitochondrial energetics to cytoprotection.

\section{INHIBITION OF MYOCARDIAL DYSTROPHIN} PROTEOLYSIS

Recent exciting data have shown that NO inactivates coxsackieviral protease 2A, which cleaves human and mouse dystrophin in a dose dependent manner. ${ }^{32}$ This provides a further novel mechanism for protection by $\mathrm{NO}$ against viral myocarditis and may explain why $\mathrm{NO}$ concentrations are significantly raised in idiopathic dilated cardiomyopathy.

\section{NO and clinical cardioprotection}

The known physiological effects of $\mathrm{NO}$ in reducing left or right ventricular filling pressure, augmenting collateral coronary flow, and inhibiting platelet aggregation ${ }^{33}$ provide a powerful theoretical basis for the routine use of $\mathrm{NO}$ in the treatment of acute coronary syndromes, myocardial infarction, and heart failure. Despite this the routine use of NO donors, such as nitrates, for clinical cardioprotection remains a controversial area. The clinical evidence for the use of $\mathrm{NO}$ in cardiovascular disease is reviewed.

\section{MYOCARDIAL INFARCTION}

In a small number of myocardial infarction trials predating the thrombolytic era intravenous nitrates were thought to have beneficial effects on infarct size and mortality. Subsequent meta-analysis of these trials indicated up to a $49 \%$ reduction in mortality with the use of prolonged intravenous glyceryl trinitrate. ${ }^{34}$ However, the later and larger megatrials such as ISIS-4 (fourth international study of infarct survival) $^{35}$ and GISSI-3 (Gruppo Italiano per lo studio della sopravvivenza nell'infarto miocardico $)^{36}$ could not confirm a beneficial effect on mortality in contradiction to previously published data. In GISSI-3 the only positive elements were a significant $10 \%$ reduction of the combined rate of death and left ventricular dysfunction in patients over the age of 70 years, and in women a more pronounced effect of lisinopril on mortality when nitrates were coprescribed. One major criticism of the ISIS-4 and GISSI-3 megatrials is the widespread use of open label oral nitrates in the placebo and control groups (62\% and 57\%, respectively), which may have diluted the true effects of nitrates in both studies. ${ }^{37}$ Of course the use of intravenous nitrates was not 
addressed in these studies and no study has specifically assessed the potential benefit of nitrate treatment before myocardial infarction. The effects of the NO donor intravenous linsidomine followed by oral molsidomine within 48 hours of myocardial infarction were studied in the ESPRIM (European study of prevention of infarct with molsidomine) trial. ${ }^{38}$ No reduction in mortality was seen but, as in the ISIS- 4 and GISSI- 3 studies, nitrates were frequently used in the placebo group.

The delay often associated with reperfusion therapy in patients with ongoing myocardial infarction provides a clear indication for the use of adjunctive cardioprotective agents. The known cytoprotective actions of NO during ischaemia-reperfusion and favourable effects on diastolic dysfunction, ${ }^{39}$ often associated with reperfusion injury, provide a rationale for the use of NO releasing agents in this context.

ANGINA

Despite clear demonstrable effects in relieving symptoms and electrocardiographic changes of ischaemia, nitrates have not been shown to influence mortality in stable or unstable angina. The observation that preinfarction angina may be a correlate of preconditioning in humans has been shown in several studies but remains controversial. In one of the largest studies analysing patients in the TIMI 4 (thrombolysis in myocardial infarction (phase 4)) study ${ }^{40}$ the presence of preinfarction angina reduced the combined end points of inhospital death, severe congestive heart failure or shock from $12 \%$ in patients with no preceding angina to $4 \%$. As expected the use of oral antianginal medication was higher in the angina group before myocardial infarction. In particular nitrate usage was $34 \%$ in the angina group compared with $14 \%$ in the no angina group, and it is interesting to speculate as to the contribution of antecedent nitrate treatment to cardioprotection.

ANGIOPLASTY

The ACCORD (angioplastie coronaire, corvasal et diltiazem) study $^{41}$ investigated the effect of direct NO donors linsidomine and molsidomine on angiographic restenosis after coronary balloon angioplasty. Pretreatment with the NO donor was associated with a modest improvement in immediate angiographic result compared with diltiazem, which was maintained at six months.

\section{HEART FAILURE}

The beneficial haemodynamic effects of nitrates in preload reduction inducing a reduction in pulmonary and left ventricular end diastolic pressure are helpful in heart failure. A recent study of the use of intravenous nitrates in acute severe pulmonary oedema showed a significant reduction in seven day mortality. ${ }^{42}$ No study has assessed the sole use of nitrates in chronic heart failure but the V-HeFT (vasodilator-heart failure) trials $\mathrm{I}$ and $\mathrm{II}^{43}$ showed that the combination of isosorbide dinitrate and hydralazine produced a $38 \%$ reduction in mortality at one year compared with placebo or prazosin. In addition favourable effects of $\mathrm{NO}$ on diastolic relaxation suggest a beneficial effect in diastolic heart failure. $^{44}$

\section{CARDIAC SURGERY}

Ischaemia-reperfusion injury is an important phenomenon during cardiac surgery and the pharmacological manipulation of cardioplegic solutions is a powerful clinical tool in the preservation of myocardial integrity. Two studies have addressed the cardioprotective role of NO during cardiac surgery by supplementation of blood cardioplegia with L-arginine ${ }^{45}$ and SPM5185, a cysteine containing NO donor. ${ }^{46}$ These agents respectively produced both reduced infarct size and improved postischaemic contractile performance. If $\mathrm{NO}$ can precondition the myocardium then $\mathrm{NO}$ releasing agents may also have a protective role before routine cardiac surgery.

\section{NO donors}

The development of a number of NO donors has allowed the investigation and application of biologically active $\mathrm{NO}$ in experimental research and therapeutic trials. However, commercially available compounds vary considerably in the rate, amount of $\mathrm{NO}$ release, and the possibility that some agents also release other radicals.

- Glyceryl trinitrate as an organic nitrate requires the biotransformation of nitrate to release NO. This is a multistep enzymatic process, involving the formation of S-nitrosothiols, dependent on the availability of glutathione.

- SIN-1 is the hepatic metabolite of molsidomine, which is available in systemic form (linsidomine). SIN-1 releases nitrate, nitrite, and superoxide anions during the liberation of NO.

- SNP, a nitroprusside dianion consisting of a complex of ferrous ion with five cyanide ions, releases $\mathrm{NO}$ by interaction with a thiol reducing agent in the presence of light.

- SNAP is a nitrosothiol that directly releases NO slowly without prior biotransformation. The long half life leads to prolonged action and stable release pharmacokinetics.

- DETA-NO is a diazenium diolate with a 20 hour half life. The prolonged duration of action opens up a therapeutic potential for this compound.

- NO aspirins are a new class of NO donors attached to an aspirin moiety originally designed for gastric mucosal protection. Examples are NCX 4016 and NCX $4215 .^{47}$

\section{Drugs with NO modulating properties} ADENOSINE

This purine nucleotide produces $\mathrm{NO}$ via the activation of constitutive NOS (cNOS). Apart from its vasodilatory and atrioventricular nodal blocking actions it is thought to be an important trigger of preconditioning in animals and patients. ${ }^{48}$ 
SILDENAFIL

Originally developed as an antihypertensive, the cyclic GMP type V phosphodiesterase inhibitor sildenafil (Viagra; Pfizer) has revolutionised the treatment of erectile impotence. Sildenafil has been shown to enhance flow mediated vasodilation in patients with chronic heart failure, ${ }^{49}$ and the development of new and more cardiospecific cyclic GMP phosphodiesterase inhibitors may well herald a new era of cardioprotective agents for use in clinical cardiology.

STATINS

Substantial interest has focused on the noncholesterol lowering or pleiotropic effects of this group of drugs. The statins have favourable effects on endothelial function and NO may be implicated in the mechanism. Pravastatin sodium has been shown to cause endothelial dependent vasorelaxation of aortic rings by activating cNOS and releasing $\mathrm{NO}$ in a dose dependent manner. ${ }^{50}$ The mechanism of cNOS activation by statins is unknown.

NICORANDIL

Nicorandil is a selective potassium dependent ATP channel blocker but also has an NO releasing moeity. It has been implicated in the preconditioning phenomenon and shown to be protective in unstable angina. ${ }^{51}$ It is possible that the NO producing effect of this drug contributes to its cardioprotective properties.

ANGIOTENSIN CONVERTING ENZYME INHIBITORS Angiotensin converting enzyme (ACE) inhibitors prevent the breakdown of bradykinin that in turn increases NO production by the activation of cNOS. ACE inhibitors appear to have a number of protective effects independent of ACE inhibition. Recent evidence suggests that this might be explained by an $\mathrm{NO}$ mediated improvement in endothelial function. ${ }^{52}$

NEVIBOLOL

Nevibolol is a new cardioselective $\beta$ blocker with NO modulating properties ${ }^{53}$ licensed for treating hypertension. However, these combined effects may prove useful in the treatment of coronary disease and heart failure.

\section{AMLODIPINE}

This calcium blocker was found unexpectedly to release NO from coronary microvessels through a kinin mediated mechanism..$^{54}$ Amlodipine also releases $\mathrm{NO}$ from coronary microvessels in human failing hearts, which may have provided a novel mechanism for its cardioprotective effects in a recent heart failure trial. $^{55}$

Evidence for the NO mediated effects of ACE inhibitors, amlodipine, and nevibolol is speculative and controversial. Further evidence is needed to explore the potential NO modulating properties of these drugs.

\section{Conclusion}

NO will remain one of nature's fascinating molecules and provide cardiovascular scientists with a tool to understand further the workings of complex physiological systems. A greater understanding of the molecular basis of NO mediated actions in cellular homeostasis will allow us to harness its actions as a potentially powerful cardioprotective agent. What is first needed is the development of more refined pharmacological NO donors together with clinical trials based on emerging biological principles. This may lead to the use of NO type agents as adjunctive pharmacotherapy for use in the future management of acute coronary syndromes, before high risk percutaneous transluminal coronary angioplasty, surgical cardioplegia, and heart failure.

1 Warren JB, Pons F, Brady AJB. Nitric oxide biology: implications for cardiovascular therapeutics. Cardiovasc Res cations for car

2 Habib FM, Springall DR, Davies GJ, et al. Tumour necrosis factor and inducible nitric oxide synthase in dilated cardiomyopathy. Lancet 1996;347:1151-5.

3 Szabolcs MJ, Ravalli S, Minanov O, et al. Apoptosis and increased expression of inducible nitric oxide synthase in human allograft rejection. Transplantation 1998;65:804-12.

4 Kelly RA, Balligand J-L, Smith TW. Nitric oxide and cardiac function. Circ Res 1996;79:363-80.

5 Akiyama K, Suzuki P, Grant P, et al. Oxidation products of nitric oxide, $\mathrm{NO}_{2}$ and $\mathrm{NO}_{3}$, in plasma after experimental myocardial infarction. $\mathcal{F} \mathrm{Mol}$ Cell Cardiol 1997;29:1-9.

6 Lecour S, Maupoil V, Zeller M, et al. Levels of nitric oxide in the heart after experimental myocardial ischaemia. $\mathcal{F}$ Cardiovasc Pharmacol 2001;37:55-63.

7 Felaco M, Grilli A, Gorbunov N, et al. Endothelial NOS expression and ischemia-reperfusion in isolated working rat heart from hypoxic and hyperoxic conditions. Biochim Biophys Acta 2000;1524:203-11.

8 Lincoln J, Hoyle CHV, Burnstock G. Basic principles and recent advances. In: Lincoln J, Hoyle CHV, Burnstock G, eds. Nitric oxide in health and disease. Cambridge: eds. Nitric oxide in health and diseas.

9 Ishida H, Ichimori K, Hirota Y, et al. Peroxynitrite-induced cardiac myocyte injury. Free Radic Biol Med 1996;20:34350

10 Beckman JS, Crow JP. Pathological implications of nitric oxide, superoxide and peroxynitrite formation. Biochem Soc Trans 1992;21:330-4.

11 Agullo L, GarciaDorado D, Inserte J, et al. L-arginine limits myocardial cell death secondary to hypoxia-reoxygenation by acGMP-dependent mechanism. Am f 1999;45:H157480 .

12 Jones SP, Girod WG, Palazzo AJ, et al. Myocardial ischemia-reperfusion injury is exaccerbated in the absence of endothelial nitric oxide synthase. Am $\mathcal{f}$ Physiol (Heart Circ Physiol) 1999;276:H1567-73.

13 Siegfried MR, Erhardt J, Rider T, et al. Cardioprotection and attenuation of endothelial dysfunction by organic nitric oxide donors in myocardial ischemia-reperfusion. F Pharmacol Exp Ther 1992;260:668-75.

14 Johnson G III, Tsao PS, Lefer AM. Cardioprotective effects of authentic nitric oxide in myocardial ischemia with reperfusion. Crit Care Med 1991;19:244-52

15 Woolfson RG, Patel VC, Nield GH, et al. Inhibition of nitric oxide synthesis reduces infarct size by an adenosinedependent mechanism. Circulation 1995;91:1545-51.

16 Cope JT, Banks D, Laubach VE, et al. Sodium nitroprusside exacerbates myocardial ischemia-reperfusion injury. Ann Thorac Surg 1997;64:1656-9.

17 Cassina A, Radi R Differential inhibitory action of nitric oxide and peroxynitrite on mitochondrial electron transport. Arch Biochem Biophys 1996;328:309-16.

18 Kim Y-M, de Vera ME, Watkins SC, et al. Nitric oxide protects cultured rat hepatocytes from tumour necrosis factor$\alpha$-induced apoptosis by inducing HSP 70 expression. $\mathcal{F}$ Biol Chem 1997;272:1402-11.

19 Siow RCM, Sato H, Mann GE Heme oxygenase-carbon monoxide signalling pathway in atherosclerosis: antimonoxide signalling pathway in atherosclerosis: antiCardiovasc Res 1999;41:385-94.

20 Lamas S, Perez-Sala D, Moncada S Nitric oxide: from discovery to the clinic. Trends Pharmacol Sci 1998;19:436-8.

21 Vinten-Johansen J, Zhao ZQ, Nakamura M, et al. Nitric oxide and the vascular endothelium in myocardial ischemia-reperfusion injury. Ann NY Acad Sci 1999;874: 354-70.

22 Brady AJB, Warren JB, Poole-Wilson PA, et al. Nitric oxide attenuates cardiac myocyte contraction. Am F Physiol 1993; 265:H176-82.

23 Rakhit RD, Edwards RJ, Mockridge JW, et al. Nitric oxideinduced cardioprotection in cultured rat ventricular myocytes. Am $\mathcal{f}$ Physiol Heart Circ Physiol 2000;278: H1211-7.

24 Bolli R, Dawn B, Tang X-L, et al. The nitric oxide hypothesis of late preconditioning. Basic Res Cardiol 1998;93:32538 .

25 Sasaaki N, Sato T, Ohler A, et al. Activation of mitochondrial ATP-dependent potassium channels by nitric oxide. drial ATP-dependent potassium
Circulation 2000;101:439-45. 
26 Ping P, Takano $\mathrm{H}$, Zhang J, et al. Isoform-selective activation of protein kinase $\mathrm{C}$ by nitric oxide in the heart of conscious Sirc Res 1999;84:587-604.

27 Budinger GRS, Duranteau J, Chandel NS, et al. Hibernation during hypoxia in cardiomyocytes. I Biol Chem 1998;273:3320-6.

28 Loke KE, McConnell PI, Tuzman JM, et al. Endogenous endothelial nitric oxide synthase-derived nitric oxide is a physiological regulator of myocardial oxygen consumption. Circ Res 1999;84:840-5.

$29 \mathrm{Xu} \mathrm{Z}-\mathrm{L}$, Endoh H, Ishihata A, et al Effect of ischaemic preconditioning on myocardial oxygen consumption during ischemia. $\mathcal{F}$ Mol Cell Cardiol 1998;30:2165-74.

30 Jennings RB, Reimer KA The cell biology of acute myocardial ischaemia. Anпu Rev Med 1991;42:225-46.

31 Rakhit RD, Mojet MH, Marber MS, et al. Mitochondria as targets for nitric oxide-induced protection during simulated ischemia and reoxygenation in isolated neonatal cardiomyocytes. Circulation 2001;103:2617-23.

32 Bardorff C, Fichtlscherer B, Rhoads RE, et al. Nitric oxide inhibits dystrophin proteolysis by coxsackieviral protease

33 Moncada S, Palmer RMJ, Higgs EA Nitric oxide: physiology, pathophysiology, and pharmacology. Pharmacol Rev 1991;43:109-42.

34 Yusuf S, Collins R, MacMahon S, et al. Effect of intravenous nitrates on mortality in acute myocardial infarction: an overview of the randomised trials. Lancet 1988;i:1088-92.

35 ISIS 4 (fourth international study of infarct survival) Collaborative Group. ISIS 4: a randomised factorial trial assessing early oral captopril, oral mononitrate and intravenous magnesium sulphate in 58,050 patients with suspected acute myocardial infarction. Lancet 1995;345: 669-85.

36 Anon. GISSI-3: effects of lisinopril and transdermal glyceryl trinitrate singly and together on 6 week mortality and ventricular function after acute myocardial infarction. Gruppo Italiano per lo studio della sopravvivenza nell'infarto Italiano per lo studio della sopravvive

37 Thadani U. Oral nitrates: more than symptomatic therapy in coronary heart disease? Cardiovasc Drugs Ther 1977;11 213-8.

38 European Study of Prevention of Infarct with Molsidomine (ESPRIM) Group. The ESPRIM trial: short-term treatment of acute myocardial infarction with molsidomine. Lancet 1994;344:91-7.

39 Paulus WJ, Vantrimpont PJ, Shah AM. Acute effects of nitric oxide on left ventricular relaxation and diastolic distensibility in humans: assessment by bicoronary sodium nitroprusside infusion. Circulation 1994;89:2070-8.

40 Kloner RA, Shook T, Przyklenk K, et al Previous angina alters in-hospital outcome in TIMI 4: a clinical correlate to preconditioning? Circulation 1995;91:37-47.

41 Lablanche JM, Grollier G, Lusson JR, et al. Effect of the direct nitric oxide donors linsidomine and molsidomine on angiographic restenosis after coronary balloon angioplasty. The ACCORD Study. Angioplastic coronaire corvasal diltiazem. Circulation 1997;95:83-9.

42 Bertini G, Giglioli C, Biggeri A, et al. Intravenous nitrates in the prehospital management of acute pulmonary oedema. Ann Emerg Med 1998;30:493-9.

43 Loeb HS, Johnson G, Henrick A, et al. Effect of enalapril, hydralazine plus isosorbide dinitrate and prazosin on hospitalisation in patients with chronic congestive heart failure. Circulation 1993;87:VI78-87.

44 Mandinov L, Eberli FR, Seiler C, et al. Diastolic heart failure. Cardiovasc Res 2000;45:813-25.

45 Sato H, Zhao ZQ, McGee DS, et al. Supplemental L-arginine during cardioplegic arrest and reperfusion avoids regional postischaemic injury. $\mathcal{F}$ Thorac Cardiovasc avoids regional postischac

46 Nakanishi K, Zhao ZQ, Vinten-Johansen J, et al. Blood cardioplegia enhanced with nitric oxide donor SPM-5185 counteracts postischemic endothelial and ventricular dysfunction. I Thorac Cardiovasc Surg 1995;109:1146-54.

47 Yamamoto T, Bing RJ. Nitric oxide donors. Proc Soc Exp Biol Med 2000;225:200-6.

48 Pomerantz BJ, Joo K, Shames BD, et al. Adenosine preconditioning reduces both pre and postischemic arrhythmias in human myocardium. F Surg Res 2000;90:191-6.

49 Katz SD, Balidemaj K, Homma S, et al. Acute type 5 phosphodiesterase inhibition with sildenafil enhances flowmediated vasodilation in patients with chronic heart failure. $7 \mathrm{Am}$ Coll Cardiol 2000;36:845-51.

50 Kaesemeyer WH, Caldwell RB, Huang J, et al. Pravastatin sodium activates endothelial nitric oxide synthase independent of its cholesterol-lowering actions. F Am Coll Cardiol 1999;36:845-51.

51 Patel DJ, Purcell HJ, Fox KM. Cardioprotection by opening of the K(ATP) channel in unstable angina. Is this a clinical manifestation of myocardial preconditioning? Results of a randomized study with nicorandil. CESAR 2 investigation. Clinical European studies in angina and revascularization. Eur Heart $\mathcal{F} 1$ 1999;20:51-7.

52 O'Driscoll G, Green D, Maiorana A, et al. Improvement of endothelial function by angiotensin-converting enzyme inhibition in non-insulin-dependent diabetes mellitus. 7 Am Coll Cardiol 1999;33:1506-11.

53 Bowman AJ, Chen CPIH, Ford GA Nitric oxide mediated venodilator effects of nevibolol. Br F Clin Pharmacol 1994; 38:199-204

54 Zhang X, Kichuk MR, Mital S, et al Amlodipine promotes kinin-mediated nitric oxide production in coronary microvessels of failing human hearts. Am f Cardiol 1999;84:27L33L.

55 Packer M, O'Connor CM, Ghali JK, et al. Effect of amlodipine on morbidity and mortality in severe chronic heart failure Prospective randomized amlodipine survival evaluation study group. $N$ Engl f Med 1996;335:1107-14.

\section{Implementing the National Service Framework for Coronary Heart Disease}

Thursday 18 October 2001

\section{Royal Marsden Conference Centre, London}

Who should attend?

- Consultant Cardiologists

- Cardiac Services Managers

- Medical Directors

- Health Authority Managers

- A\&E Practitioners
- Consultant Cardiac Surgeons

- Senior Nurses

- Public Health Consultants

- Health Promotion Managers

- Cardiac Rehabilitation Teams

For further information, please call Thushara Gibson on 02074532093 or email: thushara.gibson@informa.com 